\title{
El complejo vínculo entre Arabia Saudita e Irán y la guerra civil de Yemen
}

Agustín Dip Gilardone*

\section{Resumen}

El presente trabajo analiza los distintos intereses que guiaron las políticas exteriores del Reino de Arabia Saudita y de la República Islámica de Irán en la guerra civil de Yemen desde 2014 hasta 2017. Para ello, se abordará a través de una síntesis teórica dual (realista y constructivista) cuáles han sido los intereses que guiaron las acciones externas de los actores involucrados.

Palabras clave: Arabia Saudita - Irán - Islam - Interés - Identidad - Yemen

\section{Saudi Arabia and Iran's relations connected with Yemen's civil war}

\begin{abstract}
This paper analyzes the different interests that guided the foreign policy of the Kingdom of Saudi Arabia and the Islamic Republic of Iran at Yemens civil war from 2014 to 2017. For that aim, it will be addressed through a dual theoretical synthesis (realism and constructivism) which were the interests that guided the external actions of the actors involved.
\end{abstract}

Key words: Saudi Arabia - Iran - Islam - Interest - Identity - Yemen

TRABAJO RECIBIDO: 03/10/2019

TRABAJO ACEPTADO: 28/11/2019

\footnotetext{
* Licenciado en Relaciones Internacionales, Universidad Nacional de Rosario (UNR, Argentina). Investigador graduado del Instituto Rosario de Estudios del Mundo Árabe e Islámico (IREMAI) de la UNR. Miembro del Grupo de Estudios de Medio Oriente (GEMO) en el marco del PRECSUR y docente Adscripto en el Seminario Religión, Política y Economía en las Relaciones Internacionales del Medio Oriente y Norte de África en la Facultad de Ciencia Política y Relaciones Internacionales (UNR). Correo electrónico: dipagustin@gmail.com
} 


\section{Introducción}

La constante tensión existente entre el Reino de Arabia Saudita y la República Islámica de Irán obedece a múltiples factores. Tanto las diferencias religiosas como políticas y económicas se funden para generar un conflicto cuyas derivaciones han tenido un impacto regional sumamente importante. En este sentido, la conflagración yemení fue tan solo otro capítulo de esta rivalidad.

Ha sido común notar que cuando se hace referencia a la relación de competencia entre Arabia Saudita e Irán y al estado de tensión actual en la región de Medio Oriente y Norte de África (MENA, por sus siglas en inglés) aparecen dos supuestos: el primero, que todo se desarrolla en torno a intereses pragmáticos, mencionando la afiliación wahabita ${ }^{1}$ o chiita ${ }^{2}$ como un dato auxiliar; y el segundo, que se hace una atribución exagerada e imprecisa de dicho esquema sectario. Ninguna de las dos suposiciones es correcta por sí sola.

Para poder analizar esta interacción entre sauditas e iraníes se hace necesario adoptar un enfoque teórico dual en el que se sintetizan los aportes de dos corrientes que a simple vista resultan antitéticas. Sin embargo, cada una, con sus respectivas ontologías y metodologías específicas - materialista e idealista - nos brindan herramientas de análisis para entender los componentes de las acciones externas de los actores que intervienen en el conflicto yemení. En esas acciones, se ven cristalizados tanto los factores materiales como los ideacionales.

Los Estados formulan sus políticas exteriores en función de diversos elementos. Uno de ellos es el interés. Siguiendo al teórico de la escuela realista, Hans Morgenthau (1948), el interés es el determinante de las acciones de política exterior de los Estados en un período particular de la historia. A su vez, depende del contexto dentro del cual se formula la misma.

Sin embargo, esto es insuficiente para analizar el complejo vínculo entre la Monarquía y la República Islámica. Es por eso que se toman los aportes de la escuela constructivista de las Relaciones Internacionales, que ponen el foco en los factores ideacionales (como la religión) pero sin desconocer la importancia de los elementos materiales (Wendt, 1994). Así, se entiende a las identidades como una construcción intersubjetiva entre los diferentes actores o agentes, ya sean estatales o no estatales, en un contexto determinado (Wendt, 1994). Como dice Louise Fawcett (2016), las variaciones en las políticas exteriores de los Estados resultan de complejas interacciones entre sus identidades y sus capacidades materiales.

De esta manera, se parte de la idea de que las relaciones de Arabia Saudita e Irán con sus aliados proxy ${ }^{3}$ han estado influenciadas no sólo por nociones realistas de intereses pragmáticos sino también por identidades religiosas convergentes y/o divergentes entre los actores involucrados. Esas identidades sirvieron como facilitadoras para la creación de alianzas, tuvieron influencia en el subsecuente proceso de toma de decisiones y en la dinámica del conflicto yemení en sí mismo (Kováčiková, 2019).

En tal sentido, en el presente trabajo, se va a analizar de qué manera la religión y las cuestiones materiales influyeron en el accionar de ambas potencias regionales en la guerra civil de Yemen.

\footnotetext{
${ }^{1}$ El wahabismo es una de las corrientes del Islam sunnita (principal rama profesada por el $85 \%$ de los feligreses) que surgió en el siglo XVIII en el actual territorio de Arabia Saudita. Reivindican una interpretación rigurosa del Corán y una aplicación estricta de la Sharia.

${ }^{2}$ El chiismo es la segunda rama del Islam siendo practicada por un $15 \%$ de los musulmanes en el mundo. Consideran que el liderazgo político y religioso no puede disociarse, y que corresponde a los descendientes de Mahoma asumir el puesto de imán. Además, la corriente mayoritaria espera la llegada del imán duodécimo, quien desapareció en las esencias y permanece oculto desde el año 874; sólo regresará para restablecer el justo gobierno del Islam.

${ }^{3}$ El concepto de aliado proxy deriva de proxy war o guerra por delegación, que se refiere a un conflicto entre dos Estados, los cuales no entran en combate abierto directamente entre sí, sino que lo hacen por medio de terceros agentes o actores (Álvarez Ossorio, 2016).
} 


\section{Los hechos}

El 17 de diciembre de 2010 inició un proceso de revueltas que sacudieron a gran parte de los países que integraban la región del MENA. Ese día quedaría en la historia a partir de que el joven vendedor ambulante tunecino, Mohammed Bouazizi, se inmolara en público tras ver cómo las autoridades locales confiscaban una vez más su carro con frutas y verduras. Rápidamente, se desató una fuerte protesta en Túnez, que generó un efecto dominó, extendiéndose en los distintos países de la región como Libia, Egipto, Siria, Bahréin y Yemen. Este último caso es el que motivó el presente artículo.

En los primeros días de 2011, la denominada Primavera Árabe llegó al pequeño país árabe. Este caso tenía la particularidad de que los problemas socioeconómicos que padecía la población se vincularon de forma inexorable con las demandas por una mayor apertura política. Los altos niveles de desempleo que golpeaban principalmente a los jóvenes, la discriminación política y económica que sufrían los habitantes del sur (cuna de movimientos secesionistas) y la falta de oportunidades para el grueso de la población se encontraban entre las principales causas de las protestas (Pradhan, 2017).

Luego de la caída de Ben Alí en Túnez, el 14 de enero de 2011, una manifestación compuesta por jóvenes activistas de la sociedad civil, demandó la salida del entonces presidente Ali Abdullah Saleh (en adelante, sólo Saleh) en Yemen, quien se encontraba en el cargo desde 1990. Al mes siguiente, las protestas se expandieron a todo el país, motivadas por la caída de Mubarak en Egipto.

Saleh utilizó las fuerzas de seguridad para reprimir duramente estos movimientos; sin embargo, lo único que logró fue que su legitimidad se viera lesionada. Tras un enorme esfuerzo político y diplomático de Arabia Saudita y del Consejo de Cooperación del Golfo (CCG), Saleh aceptó renunciar y ceder el cargo a su vicepresidente, Abd al-Rahman Rabbuh al-Mansur alHadi (en adelante, sólo Hadi). Sin embargo, nada cambiaría con el nuevo jefe de Estado. De hecho, las condiciones de seguridad empeoraron gradualmente. A su vez, la economía seguía siendo manejada por las mismas 10 familias que lo habían hecho durante últimos los treinta años. Lógicamente, esto era percibido como una continuación de la política de Saleh.

En 2014 un nuevo actor comenzó a jugar un rol clave, transformando el escenario yemení completamente. Ese fue el caso del grupo insurgente Ansar Allah, también llamado al Houthi (o Hutíes) proveniente del norte del país y perteneciente a la secta religiosa zaidí ${ }^{4}$, que es una rama del chiismo. Este movimiento tuvo como objetivo establecer un imanato ${ }^{5}$ (Hill, 2017). En la década del noventa comenzaron su accionar en la provincia de Saada como respuesta a la influencia del Islam salafista ${ }^{6}$ en la región, auspiciada por Arabia Saudita. Acusaban al gobierno de corrupción, negligencia, de permitir la creciente influencia del wahabismo en el país y de alinearse con los Estados Unidos. A partir de 2004, la situación de seguridad empeoró debido a los frecuentes choques entre los Hutíes y las fuerzas del gobierno. Además, los intentos de mantener la estabilidad mediante un alto al fuego por parte del gobierno fracasaron en numerosas oportunidades (Pradhan, 2017).

Desde sus inicios, el conflicto de Yemen ha sido visto por los medios internacionales como uno de naturaleza exclusivamente sectaria en el que las potencias regionales, a saber, Arabia Saudita e Irán, explotaron las debilidades internas de dicho país para su propio beneficio. En este trabajo se pondrá de manifiesto cómo, en realidad, el sectarismo fue "activado desde

\footnotetext{
${ }^{4}$ El zaidismo es una rama del chiismo que aparece en el siglo VIII. A diferencia de los chiitas, no reconocen al quinto imán ni creen que éste sea infalible dado que no está guiado por Alá.

${ }^{5}$ El imanato se refiere a una forma de gobierno teocrática donde la máxima autoridad es el imán.

${ }^{6}$ El Islam salafista o salafismo es un movimiento ultraconservador del Islam que promueve el regreso a la interpretación tradicional y literal del Corán.
} 
afuera" por sauditas e iraníes para perseguir sus intereses de política exterior (Perteghella, 2018).

En este sentido, resulta importante identificar cuáles han sido dichos intereses. Para ello, se procede a identificar tres tipos de intereses: los geopolíticos, los energéticos y los religiosos que se desarrollan a continuación.

\section{Los intereses geopolíticos}

La Primavera Árabe alentó a que la monarquía de la familia Saúd ejerciera una política exterior proactiva y agresiva en los conflictos regionales, dejando atrás una actitud tradicionalmente pasiva. Esto se debe en gran parte a que coincidió con un cambio generacional que se gestó en la elite política saudita. En este sentido, la llegada al poder del rey Salman en 2015 y de su hijo, el príncipe heredero Mohammed Bin Salman, a cargo del Ministerio de Defensa, representó un parte aguas en la conducción de la agenda externa a partir de la promoción de una política más impetuosa con respecto a sus vecinos (Kinnimont, 2016). En este sentido, Yemen representó un claro ejemplo de dicha política.

Desde el punto de vista geopolítico, los siguientes elementos revelaron la importancia que tenía Yemen para el Reino de Arabia Saudita: la ubicación, el tráfico marítimo, la presencia de grupos terroristas.

Toda alteración en el terreno yemení representaba una gran amenaza para el interés de seguridad nacional saudí debido a su ubicación, al sudoeste de la Península Arábiga, y por compartir una frontera de 1.458 kilómetros de largo. Tradicionalmente, la política saudita hacia el pequeño país árabe se condujo más por un deseo de preservar la estabilidad que de utilizar al país como un escenario para un conflicto regional con Irán (Pradhan, 2017). Los Saud trataron a Yemen como si fuese uno de sus territorios, interviniendo en la política doméstica, definiendo agendas y sosteniendo al entonces presidente $\mathrm{Saleh}^{7}$ (Fraihat, 2016). Por tal motivo, lo que interesaba a Ryad en esta conflagración era restaurar la legitimidad del presidente Hadi, forzado a renunciar por parte de los rebeldes Hutíes en 2015, y a partir de ahí lograr la estabilización del país. De esta manera, si lograban un Yemen relativamente estable y financieramente dependiente de Arabia Saudita volverían a generar un aliado en su frontera sur, disuadiendo todo elemento de inseguridad e inestabilidad (Pradhan, 2017).

Otra clave geopolítica para entender el accionar saudita se deriva del hecho de que tanto el territorio continental yemení como sus islas adyacentes al oeste han jugado un rol crítico en la seguridad del estrecho Bab el-Mandeb, al sudeste del Mar Rojo, también llamado la Puerta de Lágrimas $^{8}$. Rodeado por Yemen, Djibouti, Eritrea y Somalía, dicho estrecho ha sido el punto de paso entre el Cuerno de África y Medio Oriente, que permitió conectar el Mar Rojo con el Golfo de Aden y a éste con el Mar Arábigo. Ante esta realidad, la Monarquía tuvo en consideración la seguridad de los buques de carga que atravesaban el canal de Suez y la estabilidad económica de Egipto, la seguridad del puerto saudí de Jeddah, y la presencia de la mayor planta de exportación de petróleo off-shore fuera de la Península (Cordesman, 2015).

Respecto del tráfico marítimo, la mayor parte de las exportaciones provenientes del Golfo Pérsico atravesaban el Canal de Suez, lo que indefectiblemente hacía que tuviesen que atravesar por el estrecho. De hecho, se estimó que alrededor de tres millones de barriles de petróleo transitaban por allí diariamente (Osman, 2014).

A ello, se le sumó la presencia de varios puertos estratégicos para el Golfo Arábigo: el puerto de Mocha en el Mar Rojo (el más antiguo de toda la Península), el de Hodeida (segundo

\footnotetext{
${ }^{7}$ La amistad que gozaban Arabia Saudita y el ex presidente Saleh servía a los intereses de ambos. El Reino evitaba amenazas del sur mientras que Saleh recibía ayuda financiera y apoyo político regional.

${ }^{8} \mathrm{El}$ estrecho derivaba su nombre de los peligros que implica su navegación. Según la leyenda árabe, se refiere a los miles de ahogados por el terremoto que separó a Arabia del Cuerno de África.
} 
puerto de Yemen, situado en el medio de la costa sobre el Mar Rojo) y el puerto de Saleef (que debido a su calado podía recibir buques que cargaban hasta 55.000 toneladas). Otros enclaves menores, pero de igual importancia, fueron los de Qana, Nashtun, Shahr, Mukalla y Balhaf.

Frente a esta realidad geográfica objetiva, resultaba lógico suponer que cualquier hostilidad en Yemen amenazaba todo el tráfico a través del Canal de Suez, una de las principales vías de navegación del mundo. Al ser el principal exportador de petróleo de Medio Oriente, esa ruta naval era crucial para los intereses de la economía de Arabia Saudita.

Otro de los elementos que resultó de importancia para la seguridad nacional saudí se vinculó con la presencia de grupos considerados terroristas. Principalmente, fueron dos las organizaciones que amenazaron mayormente al Reino.

Por un lado, la filial más activa de la organización liderada anteriormente por Osama Bin Laden, Al Qaeda en la Península Arábiga (AQAP). Luego de las protestas de 2011, AQAP logró consolidarse en el sudeste del país en provincias como Abyan, Zinjibar y Hadramut (Pradhan, 2017). De acuerdo con Prasantha Kumar Pradhan (2017), Al Qaeda manejaba un mini-Estado en la ciudad portuaria de Muqalla, donde se hizo con cien millones de dólares del banco central yemení.

Por el otro, el Estado Islámico también logró establecerse en Yemen, pero a un ritmo y escalas menores que AQAP. No obstante, el autodenominado califato se benefició de la consecuente fragmentación que siguió a la caída de Saleh aprovechando la oportunidad para consolidarse en territorio yemení. De ese modo, su presencia igualmente representaba una amenaza menor para el Reino que AQAP.

En este sentido, la política de intervención de Ryad en Yemen también fue influenciada por las crecientes operaciones de Al Qaeda en la Península Arábiga (Pradhan, 2017). La Monarquía era consciente que un Estado fallido al sur de su frontera devenía en una amenaza múltiple para su propia seguridad nacional. Ello respondía a que se vieron desafiados por AQAP en el propio territorio saudita, con una serie atentados.

Por último, uno de los intereses geopolíticos más importante de Arabia Saudita, fue disminuir la influencia de Teherán en Yemen. A pesar de ello, su accionar solo logró lo contrario. No obstante, hay analistas que aseguran que los objetivos sauditas eran de otra índole, y que solamente utilizó esto como una excusa. Ulteriormente, la meta era prevenir el levantamiento de cualquier gobierno apoyado popularmente en Yemen. Paradójicamente, sus esfuerzos generaron una contra respuesta por parte de Irán (Juneau, 2016).

Es aquí que debemos atenernos al rol de la República Islámica de Irán, que encontró una gran ocasión en la guerra civil yemení para expandir su influencia. Particularmente, ha sido en la llamada "medialuna chiita"9 de Medio Oriente donde Irán ha tenido mayores posibilidades de alcanzar ese objetivo. Empero, había otros países con minorías chiitas por fuera de dicha medialuna, como era el caso de Yemen. A su vez, es menester remarcar que los intereses de Irán en el pequeño país árabe eran moderados: el país no era una prioridad como sí lo eran Siria, el Líbano o Irak (Juneau, 2016). Los iraníes reconocieron públicamente que un mayor involucramiento generaba una escalada de consecuencias incalculables en las tensiones con Arabia Saudita, algo que buscaban evitar a toda costa.

Desde que se inició del conflicto, tanto Arabia Saudita, Estados Unidos como las monarquías del Golfo acusaron a Irán de brindarle su apoyo a los Hutíes. Si bien los iraníes se han encargado de desmentirlo categóricamente, hubo voces al interior del gobierno que

\footnotetext{
9 La "medialuna chiita" es una noción que surgió luego de la invasión norteamericana a Irak y fue adoptada por la rama neoconservadora de la administración Bush, Arabia Saudita y el Consejo de Cooperación del Golfo. Se trataba de un arco en la región de Medio Oriente donde la población profesaba mayoritariamente esa confesión de la religión islámica. La misma se extendía desde Bahréin aproximadamente hasta el Levante.
} 
declararon lo contrario al afirmar que Sanaa era la cuarta capital caída bajo la influencia iraní (junto con Bagdad, Beirut y Damasco) ${ }^{10}$.

La República Islámica tuvo intereses reducidos en el pequeño país árabe. Esto se vió reflejado en el impacto marginal de su presencia en el balance de poder doméstico yemení. Además, su apoyo a los Hutíes fue mínimo en comparación con los esfuerzos destinados por Arabia Saudita. Teherán entendía que una mayor presencia no tendría sentido, pudiendo llevar a un panorama regional más complejo y peligroso (Juneau, 2016).

Pese a ello, la confrontación en Yemen proveyó a los iraníes de "una circunstancia valiosa para desestabilizar, o al menos distraer, a Arabia Saudita" (Osman, 2014). Como sostiene el analista del Center for Strategic and International Studies, Anthony Cordesman, un gobierno afín hubiera permitido a la República Islámica flanquear el Golfo y desplegar bases aéreas o navales en Yemen (2015). De esa manera, la posibilidad de que Irán estableciera una pequeña pero significativa presencia en la frontera sur saudí era una realidad. De conseguirlo, Yemen se transformaba en un peón estratégico para los iraníes (Pradhan, 2017).

En términos geopolíticos, según Thomas Juneau (2016), Irán podría haber militarizado el área de tres maneras posibles: primero, colocando baterías tierra-aire a lo largo de la línea costera del Mar Rojo y en la isla de Al Mesira; segundo, podría haber repetido este accionar instalando baterías tierra-tierra en locaciones similares controlando cientos de kilómetros de territorio; y tercero, plantando minas flotantes en las rutas marítimas que atravesaban el Mar Rojo resultando, así, en una interrupción masiva del comercio mundial. De concretarse alguno de estos escenarios, la seguridad saudí se hubiera visto seriamente amenazada.

En la mentalidad iraní, involucrarse en este conflicto de forma indirecta y con un aliado proxy como los Hutíes representaba tan solo una pequeña inversión que podía otorgarle una ganancia importante sin mucho riesgo. Empero, no logró influir de manera decisiva en la dinámica del conflicto. El mínimo apoyo le trajo ganancias igualmente limitadas en términos de influencia en el terreno.

Cabe resaltar que la asistencia iraní a los Hutíes podía, en parte, comprenderse como una reacción ante los ataques saudíes: debido a esto, los zaidíes buscaron apoyo externo y sólo Irán estaba dispuesto y capacitado de proveerlo (Juneau, 2016). Ello demostró que las acciones externas eran más reactivas que proactivas.

De hecho, diversos analistas afirmaron que los Hutíes fueron más importantes para Irán y no al revés. El régimen iraní caracterizó a los Hutíes como parte del "Eje de la Resistencia", es decir, aliados en la "medialuna chiita" como Hezbollah, el régimen de al Assad en Siria y las milicias iraquíes. Sin lugar a duda, el conflicto yemení le brindó a Irán un socio en la Península Arábiga con quien presionar y amenazar a Ryad (Zimermman, 2016).

Sin embargo, los Hutíes eran conscientes que mantener una alianza para combatir por delegación una guerra de Irán podía significar un conflicto permanente con Arabia Saudita y sus propios aliados proxy (Zimermman, 2016). Para lograr el objetivo de consolidar una influencia significativa en Yemen, Irán debería haber inyectado recursos masivos, algo que no hizo a lo largo de la conflagración.

Así, vemos que ambas potencias tuvieron intereses geopolíticos en el escenario yemení. Pese a que Irán se vió favorecido por la alteración status quo peninsular, revistió mayor importancia para el Reino de Arabia Saudita.

\section{Los intereses energéticos}

${ }^{10}$ En septiembre de 2014, el parlamentario Alireza Zakani declaró públicamente que Sanaa era la cuarta ciudad árabe en unirse a la Revolución Islámica. 
La relevancia energética de Yemen se encuentra, como ya se mencionó en el apartado anterior, en su posición geográfica como punto de paso de las principales rutas marítimas. No pertenence a la Organización de Países Exportadores de Petróleo (OPEP) debido las pocas reservas comprobadas - 4 billones de barriles - de las que no se espera que alcancen más allá de los 9 años. Este hecho desestima el tradicional análisis occidental de impronta realista que afirma que los hidrocarburos son el principal interés y motor que guían las acciones externas de los Estados en el MENA.

Sin embargo, y pese a ese contexto, se puede afirmar que el Reino de Arabia Saudita sí ha tenido intereses energéticos en Yemen. Lo que buscó la Monarquía fue aprovechar el conflicto para hacerse con el control de la capacidad productiva de Yemen, por más pequeña que fuera.

En este sentido, ha sido relevante el descubrimiento de una reserva de hidrocarburos en la región de Jawf, al norte de Yemen, en la frontera con el reino saudí. En el año 2013, un grupo de expertos confirmó que allí se encontraba una de las mayores reservas energéticas del país. Esto resulta interesante puesto que sólo un $40 \%$ de la zona había sido explorada.

Diversos analistas apuntaron a que Arabia Saudita estaba interesada en controlar dicha zona, debido por ser adyacente a dos de las mayores instalaciones petrolíferas saudíes y a la provincia de Marib, rica en hidrocarburos. Más aún, como bien sostuvo Salem Farouk (2014) ante el periódico Yemen Post, la Monarquía no iba a permitir que Yemen explotase esta zona libremente puesto que le brindaría cierta independencia económica ${ }^{11}$.

En la misma línea de pensamiento, el experto en economía yemení, Mohammad Abdolrahman Sharafeddin (2017), planteó que "el 63\% de la producción de petróleo de Yemen ha sido robado por Arabia Saudita, en cooperación con Hadi y sus mercenarios". Según el mismo académico, la Monarquía estableció diversas plataformas petrolíferas en la zona sur de la región de Kharkhir (cerca de la provincia saudí de Najran) en colaboración con la compañía francesa Total Fina S.A.

Siguiendo el mismo planteo, Hassan Ali al-Sanaeri (2017) resaltó que una serie de documentos nombrados en los archivos de Wikileaks establecían que Arabia Saudita formó un comité para proyectar la construcción de un canal desde su territorio hasta el Mar Arábigo a través de la región de Hadramaut, donde se localiza Jawf ${ }^{12}$. El objetivo de esto era prescindir de los estrechos de Bab el-Mandeb y Hormuz, que se encuentran bajo soberanía iraní.

Por último, cabe destacar la convergencia de la academia en que Irán no tenía intereses energéticosen el conflicto de Yemen en particular. Sí es pertinente resaltar que un panel de expertos de Naciones Unidas afirmó que la República Islámica enviaba petróleo a los Hutíes para financiar sus actividades (Lederer, 2019).

\section{Los intereses religiosos}

Uno de los factores clave a la hora de explicar la rivalidad entre persas y sauditas es la religión. Siendo los mayores representantes de las dos principales ramas del Islam, ambas potencias buscaron proteger sus intereses religiosos.

La protección de las minorías chiitas ha sido uno de los principales intereses religiosos de la República Islámica de Irán desde la Revolución de 1979. Además, buscó colocarse como líder de la comunidad chiita y guardián del Islam. Para lograr estos objetivos, procuró expandir su influencia a lo largo de la región de Medio Oriente formando alianzas con grupos al interior

\footnotetext{
11 Yemen's hidden oil and gas reserves in Jaws a reality, Yemen Post, 19 de febrero de 2014, Sanaa. Disponible en: http://yemenpost.net/Detail123456789.aspx?SubID=7606. Consulta: 10 de julio de 2019

12 Economic Expert Discloses US-Saudi Arabia Agreement on Yemen's Oil Reserves, Tehran Times, 11 de diciembre de 2016, Teherán. Disponible en:https://www.tehrantimes.com/news/409031/EconomicExpert-Discloses- US-Saudi-Arabia-Agreement-on-Yemen-s Consulta: 11 de julio de 2019
} 
de los diversos países que profesaban doctrinas islámicas próximas al chiismo duodecimano iraní.

En este punto, es prudente utilizar el concepto de la "medialuna chiita" o "shia crescent", puesto que a partir del mismo, Irán utilizó la identidad religiosa como una forma de expandir su influencia en la región, aludiendo que debían proteger a los chiitas allí presentes. Creando este arco que atraviesa Medio Oriente por los territorios donde se encontraban la mayor cantidad de población chiita, la República Islámica justificó su expansión. De esta manera, se sostiene que la República Islámica hizo un uso instrumental de la religión para proteger sus intereses nacionales y así poder expandir su influencia en la región de Medio Oriente.

Es por eso que resulta interesante retomar lo planteado por Louise Fawcett (2016) para explicar el vínculo entre Irán y los Hutíes. Dicha autora retomó los trabajos de Alexander Wendt y afirmó que en Yemen había una guerra de identidades donde la religión se utilizó de forma instrumental para formar alianzas. Así, en términos constructivistas, Irán y los Hutíes se eligieron mutuamente como aliados proxy a partir de una identidad construida intersubjetivamente.

Ahora bien, resta comprender cómo es que se construyó dicha identidad. En este sentido, el movimiento rebelde Hutí era, como se mencionó, profesante del zaidísmo, una secta próxima al chiismo iraní. De hecho, hasta el $40 \%$ de la población yemení practicaba esa rama del Islam. Asimismo, el vínculo de los Hutíes con Irán ha sido histórico. Los rebeldes se inspiraron en la Revolución Islámica, son antioccidentales y antisauditas. De hecho, muchos clérigos zaidíes recibieron su instrucción religiosa en la localidad iraní de Qom, entre los cuales se encontraban el líder Abdul Malik al-Houthi y su hermano Hussein, quien fuese el fundador del movimiento (Pradhan, 2017).

Que hayan sido zaidíes generó dicha identificación basada en una historia religiosa en común y la misma fe. Además, esta adhesión ha sido intensificada por el conflicto con "el otro", o sea los sunnitas (Fawcett, 2016). Incluso, los Hutíes buscaron apoyo iraní adoptando frases del vocabulario del chiismo duodecimano y utilizando símbolos históricos como el nombre Hussein.

Sin embargo, hay analistas que afirmaron que no sólo la religión explicaba la alianza entre Irán y los Hutíes. De hecho, remarcaron la importancia de otros factores. Como mencionó Thomas Juneau (2016), fueron los intereses anti-status quo que compartían Irán y los Hutíes los que explicaban su alianza junto con la fe chiita. Ambos actores identificaron al orden doméstico como sostenido por los Estados Unidos y Arabia Saudita, principales rivales de los iraníes. Según este autor, era un conflicto meramente civil, en el que la rivalidad entre Irán y la monarquía saudita se sobrepuso e incluso inflamó, pero que de ninguna manera lo condujo. En la misma línea fue el académico Perteghella (2018), quien sostuvo que los intereses de los Hutíes fueron siempre políticos.

Estos factores plantean que Irán realizó un uso instrumental de la religión para perseguir su interés de expansión. De hecho, los Hutíes no eran un grupo estrictamente religioso, dado que varios miembros eran sunnitas. Más aún, había zaidíes que se les oponían (Perteghella, 2018). Incluso, su alianza con el ex presidente Saleh revistió un grado de pragmatismo, dejando de lado los ideales religiosos, puesto que éste era practicante de la confesión sunnita. Es menester remarcar que incluso los simpatizantes de Saleh miembros del ejército yemení también eran sunnitas. Empero, esto no les impidió que colaboraran con los Hutíes en su avance hacia la capital.

De esta manera, se sostiene también que el vínculo entre Irán y los Hutíes respondía a los parámetros de una alianza líquida ${ }^{13}$ debido a que se circunscribió a un tema particular que

${ }^{13}$ El concepto de "alianzas liquidas", elaborado por Eduardo Soler Lecha, se deriva de la definición que Zygmunt Bauman da a la "modernidad liquida", caracterizada por ser una situación de cambio permanente, fragilidad y vulnerabilidad. La percepción de qué o quién representa una amenaza cambia en 
ambos tenían en común, como fue la guerra de Yemen (Soler Lecha, 2017). Por un lado, Irán necesitaba de un aliado que le permitiese alterar el status quo entonces vigente en Yemen. En este sentido, los Hutíes fueron funcionales a esta necesidad coyuntural de la República Islámica. Por el otro lado, no es posible que los rebeldes se hubieran alzado en armas y obtener los resultados que alcanzaron sin el apoyo de la República Islámica.

Por el lado del Reino de Arabia Saudita, cabe destacar que el mismo se auto percibió como el líder del mundo islámico en general y de los sunnitas en particular. Esto se debe en particular a la presencia de las ciudades sagradas de La Meca y Medina ${ }^{14}$ en su territorio, puesto que han sido fuente de soft power y le otorgaron al Reino una ventaja política y religiosa en términos de legitimidad frente a la $u m m a^{15}$ o comunidad islámica (Pradhan, 2017).

Históricamente, la interpretación saudita del wahabismo ha sido conservadora, tradicionalista, políticamente quietista y subrayaba la importancia de la obediencia al gobernante y los peligros de la rebelión. Sin embargo, esta lectura obró como un arma de doble filo para la Monarquía. Era la propia naturaleza del wahabismo la que le ha impedido ganar mayor legitimidad entre los musulmanes (Wilf, 2017). Pese al hecho de ser la cuna de la religión islámica, encontró resistencias a la hora de proyectarse como el faro del mundo musulmán en la región.

En términos de interés religioso, la Monarquía buscó sostener un gobierno de corte sunnita, afín al wahabismo saudí, lo que en la práctica significó buscar el mantenimiento del status quo regional. De ese modo, el Reino auspició a Saleh en el poder durante más de 20 años para luego desestimarlo, lo que mostró cómo dicha alianza también fue líquida (Soler Lecha, 2017). Cuando en 2011 esto ocurrió, la Monarquía procuró asegurarse un aliado que velase por sus intereses en Yemen. En ese sentido, la alianza con Hadi le garantizaba cierta continuidad política y la protección de sus intereses religiosos wahabitas. De esta manera, la identidad religiosa obró también de forma instrumental para generar la alianza entre Hadi y la familia Saúd.

Necesitado de apoyo político y recursos materiales, Hadi tomó narrativas sectarias y situó su lucha contra los Hutíes en la meta-narrativa regional (Darwich, 2018). Acabó adoptando un discurso anti chiita en su confrontación con los Hutíes para mantener el apoyo de los países del Golfo, quienes percibían a la expansión de Irán en la región como la amenaza más peligrosa. Es pertinente remarcar que la monarquía saudita ha visto el conflicto con los Hutíes como una lucha ideológica contra Irán (Al-Rasheed, 2015).

Asimismo, el reino saudita necesitó del sectarismo para justificar la necesidad de una intervención militar en territorio yemení (Darwich, 2018). En esa misma línea, la investigadora Luiza Giménez Cerioli (2018) afirmó que la familia Saud se vió beneficiada por el discurso sectario, al encasillar a los Hutíes como peones de la causa chiita y como la principal fuente de inestabilidad de la región. Sin embargo, esto obró negativamente frente a los ojos de la comunidad internacional. Por eso mismo, Arabia Saudita afirmó que el conflicto con los Hutíes no era una guerra sectaria sino una operación contra rebeldes que estaban menoscabando la seguridad y estabilidad del país (Pradhan, 2017). De esta manera, intentaron descartar las acusaciones de la naturaleza religiosa y sectaria del conflicto.

función de acontecimientos puntuales y es así como proliferan alianzas líquidas que se adaptan al relieve. A su vez, las rivalidades también son líquidas: actores tradicionalmente enemistados que hacen frente común en un tema concreto sin con ello reconocerse como aliados.

14 Ambas ciudades han sido consideradas como "los dos santos lugares" por los musulmanes. La Meca fue la ciudad natal de Mahoma y el destino del peregrinaje anual llamado Hajj, uno de los cinco pilares de la religión islámica. Medina es la segunda ciudad santa del Islam, dado que allí enterraron al profeta Mahoma.

${ }^{15}$ La umma se refiere a la comunidad de creyentes islámicos. Es un concepto en el cual no se distingue a los feligreses por su estatus social, nacionalidad, origen, sexo o lugar de residencia. 
En función de lo dicho hasta aquí, se sostiene que el sectarismo fue producto de la instrumentalización de la religión que hicieron Arabia Saudita, Irán, Hadi, Saleh y los Hutíes en la guerra de Yemen. Esto generó que el conflicto haya sido menos localizado y considerablemente internacionalizado, lo que hizo que la resolución del mismo sea más dificultosa. En otras palabras, la guerra acabó sufriendo una dinámica de "sectarianización" o politización de las identidades religiosas. Así, más que inherente al conflicto o al país, el sectarismo fue "activado desde afuera" por Arabia Saudita e Irán (Perteghella, 2018).

En la misma línea, Louise Fawcett (2016) afirmó que "la securitización de las identidades sectarias en Yemen fue la principal herramienta a través de la cual, tanto Arabia Saudita como Irán, intentaron capitalizar la inestabilidad doméstica".

\section{Conclusiones}

Luego de considerar los intereses en juego, se sostiene que tanto Arabia Saudita como Irán hicieron un uso instrumental de la religión con la intención de generar alianzas por medio de identidades intersubjetivamente construidas con los distintos actores involucrados y así perseguir sus intereses geopolíticos. De este modo, la religión ha sido funcional a ambos Estados: por el lado de la República Islámica, para expandir su influencia; por el lado de la Monarquía, para mantener el status quo regional.

Por el lado de la Republica Islámica, cabe decir que, tradicionalmente, uno de sus principales intereses religiosos ha sido la protección de las minorías chiitas. Mediante esto, Irán justificaba su expansión, formando alianzas con diferentes grupos afines al interior de los Estados, como fueron en este caso de estudio los Hutíes. Sin embargo, hubo una correspondencia en esa elección puesto que, como afirmó Louise Fawcett, rebeldes e iraníes se eligieron mutuamente a partir de una identidad construida intersubjetivamente basada en la religión (Fawcett, 2016).

Más aún, los Hutíes se inclinaron por el ex presidente Saleh luego de su renuncia. Ambos actores, que habían estado enemistados por más de 20 años, confluyeron en la necesidad coyuntural de derrocar al entonces presidente Hadi. De esta forma, construyeron un frente común en lo que se denominó una alianza líquida.

Resulta interesante notar que Irán vio en este conflicto una oportunidad única para expandir su influencia en una zona que le estaba vetada. Sus intereses en Yemen fueron moderados debido a que no lo calificaron como una prioridad de política exterior. Empero, la presencia de un amplio número de población chiita resultó un gran aliciente a la hora de gestar su alianza líquida con los Hutíes. De ese modo, y al momento de actuar, buscaron alterar el status quo peninsular sin llamar la atención de Arabia Saudita y que eso los llevase a un enfrentamiento directo.

Por el lado de Arabia Saudita, estos buscaron sostener un gobierno sunnita debido a que era funcional a su interés religioso puesto que ello implicaba una perpetuación del status quo. Primero, sostuvieron a Saleh en el poder durante dos décadas hasta que no les quedó otra opción más que resignar dicho apoyo. Segundo, buscaron por todos los medios reinstalar en el poder a Hadi, también practicante del sunnismo y afín a la Monarquía. Sin embargo, sus objetivos para el escenario yemení estuvieron lejos de cumplirse. No sólo no lograron reinstalar a Hadi en el poder sino que acabaron envueltos en un conflicto de alta intensidad con un rival que, en los papeles, debería haber sido derrotado fácilmente. Sin embargo, los hechos demostraron todo lo contrario, extendiéndose en el tiempo la Guerra Civil de Yemen. 


\section{Bibliografía}

AL RASHEED, M. (2015). Saudi war in Yemen impossible to win, Al Monitor. Disponible en: https://www.al-monitor.com/pulse/fr/originals/2015/10/saudi- $\quad$ arabia-lose-protracted-waryemen.html Consulta: 2 de julio de 2019

CORDESMAN, A. (2015). The Iranian Sea-Air-Missile Threat to Gulf Shipping. Center for Strategic and International Studies. Disponible en: https://www.csis.org/analysis/iranian-sea-airmissile-threat-gulf-shipping-0 . Consulta: 10 de julio de 2019

DARWICH, M. (2018). The Saudi Intervention in Yemen: Struggling for Status, en Gulf on the Verge. Global Challenges and Regional Dynamics, Insight Turkey, 20 (2). Disponible en: https://www.insightturkey.com/author/may-darwich. Consulta: 10 de julio de 2019

FAWCETT, L. (2016). International relations of the Middle East. Oxford University Press

FRAIHAT, I. (2016). Unfinished revolutions: Yemen, Libya and Tunisia after the Arab Spring. Yale University Press

GIMÉNEZ CERIOLI, L. (2018). Roles and international behaviour: Saudi-Iranian Rivalry in Bahrain's and Yemen's Arab Spring, Contexto Internacional, 40 (2). Disponible en: http://www.scielo.br/pdf/cint/v40n2/0102-8529-cint-2018400200295.pdf. Consulta: 10 de julio de 2019

HILL, G. (2017). Yemen Endures, Oxford University Press

JUNEAU, T. (2016). Iran's policy towards the Houthis in Yemen: A limited return on a modest investment, International Affairs, 92(3), pp. 647-663. Disponible en: https://www.researchgate.net/publication/302064592 Iran's policy towards the

Houthis in Yemen A limited return on a modest investment. Consulta: 10 de julio de 2019

KINNIMONT, J. 2016. La política exterior saudí. Anuario CIDOB. Recuperado de: http://anuariocidob.org/la-politica-exterior-saudi/

KOVÁČIKOVÁ, Z. (2019). Balance of Identity and Balance of Power: The Case of Conflict Dynamics between Saudi Arabia and Iran. Disponible en: https://www.academia.edu/39894509/Balance of Identity and Balance of Power The Case of_Conflict_Dynamics_between_Saudi_Arabia_and_Iran_MA_diss._Charles_University_2019 _. Consulta: 10 de julio de 2019

LEDERER, E. (2019). UN experts: Fuel from Iranis financing Yemen rebels' war, Associated Press, 19 de enero de 2019, New York. Disponible en: https://www.apnews.com/b406265e1c6642fd9a614416270263b6 . Consulta: 10 de julio de 2019

MORGENTHAU, H. (1948). Politics Among Nations, McGraw-Hill Education

OSMAN, T. (2014). Imagining a new Arab Order, The Cairo Review. Disponible en: https://www.thecairoreview.com/tahrir-forum/imagining-a-new-arab-order/ . Consulta: 6 de julio de 2019

PERTEGHELLA, A. (2018). Yemen: the sectarianization of a political conflict. Italian institute for international political studies. Disponible en: https://www.ispionline.it/en/pubblicazione/yemen-sectarianization-political-conflict-19933 Consulta: 8 de agosto de 2019

PRADHAN, P. K. (2017). Arab Spring and sectarian faultlines in west Asia, Pentagon Press

SOLER LECHA, E. (2017). Alianzas líquidas en Medio Oriente, Anuario Cidob Internacional. http://anuariocidob.org/alianzas-liquidas-en-oriente-medio/. Consulta: 1 de julio de 2019 
WENDT, A. 1992. Anarchy is what states make of it: the social construction of power politics, International Organization, 46 (2), pp. 391-425. Disponible en: https://www.researchgate.net/profile/Alexander Wendt3/publication/227392580

_Anarchy_is_What_States_Make_of_It_The_Social_Construction_of_Power_P olitics/links/5783e3f108ae37d3af6c1303/Anarchy-is-What-States-Make-of-It-

The-SocialConstruction-of-Power-Po. Consulta: 2 de julio de 2019

WILF, E. (2017). The battle for hegemony in the Middle East, Australian Strategic Policy Institute. Disponible en:https://www.aspi.org.au/index.php/report/battle-hegemony-middle-east Consulta: 16 de julio de 2019

ZIMMERMAN, K. (2016). Signaling Saudi Arabia: Iranian support to Yemens al Houthis, Critical Threats. Disponible en: https://www.criticalthreats.org/analysis/signaling-saudi-arabiairanian-support- to-yemens-al-houthis. Consulta: 16 de julio de 2019 